\title{
вмј Global Health Cost of integrated chronic care for severe non-communicable diseases at district hospitals in rural Rwanda
}

Lauren Anne Eberly, ${ }^{1}$ Christian Rusangwa, ${ }^{2}$ Loise Ng'ang $a,{ }^{2}$ Claire C Neal, ${ }^{3}$ Jean Paul Mukundiyukuri, ${ }^{2}$ Egide Mpanusingo, ${ }^{2}$ Jean Claude Mungunga, ${ }^{4}$ Hamissy Habineza, ${ }^{2}$ Todd Anderson, ${ }^{2}$ Gedeon Ngoga, ${ }^{2}$ Symaque Dusabeyezu, ${ }^{2}$ Gene Kwan, ${ }^{5,6}$ Charlotte Bavuma, ${ }^{2,7}$ Emmanual Rusingiza, ${ }^{2,8}$ Francis Mutabazi, ${ }^{2}$ Joseph Mucumbitsi, ${ }^{9}$ Cyprien Gahamanyi, ${ }^{2}$ Cadet Mutumbira, ${ }^{2}$ Paul H Park, ${ }^{4,6}$ Tharcisse Mpunga, ${ }^{10}$ Gene Bukhman ${ }^{1,4,6}$

To cite: Eberly LA, Rusangwa C, Ng'ang'a L, et al. Cost of integrated chronic care for severe noncommunicable diseases at district hospitals in rural Rwanda. BMJ Global Health 2019;4:e001449. doi:10.1136/ bmjgh-2019-001449

Handling editor Seye Abimbola

- Additional material is published online only. To view please visit the journal online (http://dx.doi.org/10. 1136bmjgh-2019-001449).

LAE and CR contributed equally.

Received 30 January 2019 Revised 29 April 2019 Accepted 4 May 2019

Check for updates

(c) Author(s) (or their employer(s)) 2019. Re-use permitted under CC BY-NC. No commercial re-use. See rights and permissions. Published by BMJ.

For numbered affiliations see end of article.

Correspondence to

Dr Gene Bukhman;

gbukhman@bwh.harvard.edu

\section{ABSTRACT}

Background Integrated clinical strategies to address non-communicable disease (NCDs) in sub-Saharan Africa have largely been directed to prevention and treatment of common conditions at primary health centres. This study examines the cost of organising integrated nurse-driven, physician-supervised chronic care for more severe NCDs at an outpatient specialty clinic associated with a district hospital in rural Rwanda. Conditions addressed included type 1 and type 2 diabetes, chronic respiratory disease, heart failure and rheumatic heart disease.

Methods A retrospective costing analysis was conducted from the facility perspective using data from administrative sources and the electronic medical record systems of Butaro District Hospital in rural Rwanda. We determined initial startup and annual operating financial cost of the Butaro district advanced NCD clinic for the fiscal year 2013-2014. Perpatient annual cost by disease category was determined. Results A total of US\$47 976 in fixed start-up costs was necessary to establish a new advanced NCD clinic serving a population of approximately 300000 people (US\$0.16 per capita). The additional annual operating cost for this clinic was US\$68975 (US\$0.23 per capita) to manage a 632-patient cohort and provide training, supervision and mentorship to primary health centres. Labour comprised $54 \%$ of total cost, followed by medications at $17 \%$. Diabetes mellitus had the highest annual cost per patient (US\$151), followed by heart failure (US\$104), driven primarily by medication therapy and laboratory testing. Conclusions This is the first study to evaluate the costs of integrated, decentralised chronic care for some severe NCDs in rural sub-Saharan Africa. The findings show that these services may be affordable to governments even in the most constrained health systems.

\section{INTRODUCTION}

There has been increasing recognition of the importance of interventions to address non-communicable diseases (NCDs) on the path to Universal Health Coverage. ${ }^{12}$ There are equity and operational concerns

\section{Key questions}

What is already known about this topic?

- Existing costing analyses for implementation of non-communicable disease (NCD) care in highly constrained health systems have been directed to prevention of behavioural risk factors and treatment of common conditions at primary health centres or rely on modelling, leaving uncertainty.

- This study is the first to evaluate the cost of decentralised integrated nurse-driven, physician-supervised chronic care at an outpatient district-level clinic for severe NCDs in sub-Saharan Africa, such as type 1 diabetes and advanced rheumatic heart disease.

What are the new findings?

- A total of US\$47 976 was necessary to initiate an advanced NCD clinic to serve a population of approximately 300000 people (US\$0.16 per capita).

- The annual operating cost for the clinic was US\$68 975 (US\$0.23 per capita) to manage a 632-patient cohort, with labor and medications as the most significant drivers of cost.

Recommendations for policy

- The cost of decentralising integrated care for complex NCDs from tertiary referral centres to first-level hospital outpatient clinics may be affordable for governments even in the most constrained health systems.

that argue for an initial focus on delivery of cost-effective interventions to address more severe conditions affecting children and young adults. ${ }^{13}$ However, integrated clinical strategies to address NCDs in sub-Saharan Africa have largely been directed to prevention of behavioural risk factors and treatment of common conditions at primary health centres. $^{4-10}$ 
In 2006, the Rwandan Ministry of Health (RMOH) began to work with the non-governmental organisation Inshuti Mu Buzima (IMB)/Partners In Health (PIH-Rwanda) to decentralise and integrate chronic care services for severe NCDs by developing specialised nurse-led, physician-supervised outpatient advanced NCD clinics associated with rural district hospitals. ${ }^{11}$ Conditions addressed included type 1 and type 2 diabetes mellitus (DM), chronic respiratory disease (CRD), hypertension (HTN), heart failure (HF) due to advanced rheumatic and congenital heart disease, and cardiomyopathies. Nurse-provided services include simplified echocardiography, titration of diuretics, angiotensin converting enzyme inhibitors, beta-blockers, warfarin, inhaled beta-agonists, corticosteroids and insulin, and postcardiac surgical follow-up. ${ }^{12}$ This 'PEN-Plus' approach, which is complementary to the existing WHO Package of Essential Noncommunicable Disease (PEN) strategy, has been shown to be an effective way to address the NCD burden for rural poor, who often are unable to reach referral centres for care. ${ }^{912-16}$

Data on costs of delivering care are essential for governments seeking to make investments in NCD care. Existing costing strategies for NCD implementation have often relied on modelling, leaving uncertainty due to real-world variation in prices and practice patterns. ${ }^{45}$ Additionally, costing strategies based on management pathways for individual diseases may not reflect economies of scope through integrated delivery strategies. ${ }^{6}$ The operating costs of advanced NCD clinics in Rwanda were previously estimated at US $\$ 1.5$ per capita as part of prospective planning. ${ }^{11}$ However, the actual start-up costs for these advanced NCD clinics and their annual operating costs have not been previously evaluated.

This project used a microcosting approach to determine the initial start-up and annual operating financial costs of a public-sector advanced NCD clinic in the Burera district of northern Rwanda.

\section{METHODS \\ Implementation of an integrated outpatient chronic care programme for severe NCDs at first-level hospitals}

Beginning in 2006, the RMOH, supported by IMB/PIH, worked with local and international specialist physicians to train an initial cohort of nurses and establish outpatient specialty clinics for advanced NCDs in two public district hospitals (Kirehe and Rwinkwavu in Southern Kayonza: approximate combined population of about 680000 in 2012, respectively). ${ }^{11} 17$ In 2009, staff at the Southern Kayonza clinic trained nurses who went on to establish an additional clinic at Butaro Hospital in Burera district (approximate population of about 300000 in 2012). Equipment at the Butaro NCD clinic included automated blood pressure cuffs, portable ultrasound equipment (SonoSite MicroMaxx) with a dedicated cardiac probe, point-of-care international normalised ratio (INR) machine (Coagucheck Pro II), glucometers and haemoglobin A1c (HbA1c) equipment (SD Biosensor SD A1c Care). General hospital laboratory services were used. Available cardiac medications include furosemide, carvedilol, atenolol, lisinopril, captopril, hydrochlorothiazide, spironolactone, amlodipine, hydralazine, warfarin and aspirin; available medications for DM include insulin, metformin and glibenclamide; and available medications for CRD include beclamethasone and salbutamol inhalation therapy, and oral corticosteroids. Care was provided in the context of an integrated clinic, allowing patients to benefit from shared infrastructure, equipment, monitoring systems for visit scheduling and patient tracking, and a consistent team of providers. ${ }^{11}$ $\mathrm{RMOH}$ and IMB/PIH partnered to fund implementation of the clinic: IMB/PIH financed the building of the clinic space and $70 \%$ of labour costs, procured clinical equipment and medications, provided social support to patients and trained local staff. The RMOH paid for the remaining labour costs as well as the cost of laboratory testing through available equipment, facility maintenance and fees, and consumables. There is an ongoing collaboration at this site, and it continues to be a training hub supporting other districts in the country.

The conditions addressed at the Butaro-district NCD clinic are severe chronic NCDs, which include HF due to cardiomyopathies, advanced rheumatic and congenital heart disease before and after cardiac surgery, severe HTN (systolic blood pressure $>180 \mathrm{~mm} \mathrm{Hg}$ and/or diastolic blood pressure $>120 \mathrm{~mm} \mathrm{Hg}$ ), types 1 and $2 \mathrm{DM}$ requiring insulin, and CRD requiring inhaler therapy. Patients are referred to these clinics following hospital discharge, from hospital general outpatient departments and from primary health centres.

The clinical teams at the Butaro-district NCD clinic includes two nurses, a data officer and a clerk, and are supervised periodically by a general physician based at the associated Butaro District Hospital. Nurses have received 3 years of post-secondary education (A0 level) or secondary-school vocational training in nursing (A1 level). Nurses initially received 3 months of didactic training and precepted clinical practice, with 16 days devoted to HF and echocardiography.

Once in practice, nurses at this NCD clinic divide their time between direct patient care and training, supervision and mentorship of staff at lower-level facilities (primary health centres). ${ }^{18}$ Advanced NCD nurses thus support the decentralisation of more standardised care for less complex and severe conditions such as uncomplicated CRD, HTN and type 2 DM on oral therapy as part of an integrated chronic care strategy. ${ }^{19}$

After their initial training, nurses receive monthly mentorship by a cardiologist and endocrinologist during outreach visits to see complex cases and confirm diagnoses. Complete diagnostic and therapeutic protocols, which are available online, allow for nurse initiation and titration of medical therapy. ${ }^{11}$ Clinical data are recorded in paper charts, which are then entered to an electronic medical record (EMR) (OpenMRS) by the data officer. 


\section{Costing analysis}

We conducted a retrospective costing analysis using data from the administrative systems and EMR of the Butaro-district NCD clinic. We assessed financial costs, rather than economic costs, during the 2014 fiscal year (FY) (1 July 2013 to 30 June 2014) by direct measurement. Each of the following sources were reviewed for relevant items, and thus provided data for the study: Butaro District Hospital Balance Sheet and PIH Rwanda NCD Program Balance Sheet for initial hospital construction and start-up costs; Butaro District Hospital Balance Sheet for the complete 2014 FY (July 2013-July 2014), Rwanda NCD FY 2014 Program Balance Sheet (July 2013-June 2014), PIH Burera District Budget, PIH and Burera District Pharmacy Invoices, and Burera District Hospital Laboratory Invoice.

Finally, programme data on patients diagnosed and treated for NCDs (including DM types 1 and 2, HTN, HF and CRD) between July 2013 and June 2014 and the EMR were reviewed and used to determine variable costs as detailed below. The FY 2014 was chosen specifically as this was the year the clinic reached a steady state of patient volume. All costs paid in Rwandan francs were converted to US dollars by using the conversion rate at the time if available. Otherwise, the median 2014 exchange rate of 674 Rwandan francs to US\$1 was used.

\section{Fixed costs}

Fixed costs are defined as those that are independent of the number of patients treated and can be divided into one-time non-recurrent start-up costs and annualised facilities and maintenance costs. All one-time capital expenditures associated with the Butaro NCD clinic were identified. This included construction of the clinic space, purchase of clinic supplies and equipment, and baseline NCD nurse clinical training. Given that the clinic space was constructed as part of the larger hospital, a proportion of the total hospital construction cost was allotted to the NCD clinic construction based on square footage. Clinical equipment and supplies included all equipment necessary to run the NCD clinic, such as portable ultrasound (SonoSite MicroMaxx), blood pressure cuffs, point-of-care HbA1c (SD Biosensor SD A1c Care) and glucometer machines, point-of-care INR machine (Coagucheck Pro II), medical gloves and other basic medical supplies, and paper patient charts. Baseline training costs included all costs related to the initial 3-month NCD training in which two nurses were trained by one expert doctor trainer, one expert nurse trainer, two nurse trainers, one coordinator and one curriculum specialist. As a train-the-trainer initiative, limited training costs are ongoing; however, the bulk of the training cost was a one-time expense to establish a fundamental NCD knowledge base among the participating nurse trainees. For each cost, we included the actual price paid by the programme.

To determine annualised facility and maintenance costs, first shared fixed-cost categories, such as electricity, utilities, repairs and maintenance, programmatic costs and expenses, were calculated by determining the cost for services for the entire hospital and then allotting a percentage of the total to the NCD clinic based on square footage. Otherwise, each of the data sources were reviewed line by line for relevant items to be allotted to the NCD clinic. The totals of the shared fixed-cost categories were added to the costs directly associated with the NCD clinic to determine the total fixed cost of the NCD programme, with all facilities and maintenance costs annualised.

\section{Variable costs}

Variable costs are those that depend on patient volume and consumption. These costs include medications, laboratory tests, social support and labour.

\section{Medications and miscellaneous consumables}

We reviewed the EMR to identify all patients for each NCD category treated at the NCD clinic during the time of the study. All medications that patients with NCD were taking during this time were extracted by disease type, including medication name, dose, frequency as well as the number of days on the medication. The unit cost for medication was obtained from pharmacy invoices. The unit cost per medication was multiplied by the frequency and total days on the medication to determine the total cost per medication for the FY. The total medication cost was determined for NCD-specific medications only and did not include therapies related to HIV or oncology. These were summed to determine the total medication cost. Shared consumables for the entire clinic were estimated based on quarterly supply orders; disease-specific consumables were similarly extracted and included ultrasound gel for cardiac ultrasound (patients with HF) and peak flow meters (patients with CRD).

\section{Laboratory tests}

Given that laboratory data were not routinely entered into the electronic medical record until 2015, we extracted the number and type of laboratory testing by disease type during 2015. The ratio of each test per patient for 2015 was determined, then multiplied by the number of patients in each disease type enrolled in the clinic during the 2014 FY (1 July 2013 to 30 June 2014) to more accurately estimate the number of laboratory tests performed during our period of interest. The cost per each laboratory test was extracted from the district laboratory invoice and then multiplied by the number of tests to determine total annual cost per laboratory test. All laboratory tests were summed for a total annual laboratory cost.

For point-of-care testing such as INR, glucose and HbA1c, the number of tests was similarly estimated as above. The number of tests was then multiplied by the sum of the cost of the cartridge and testing strip to estimate the total cost of point of care laboratory tests. This provided an estimated annual cost based on actual practice. 


\section{Social support}

Given high loss-to-follow-up rates in low-income countries, social support was included as it is often necessary to ensure successful patient care. Relevant costs included transportation to and from the clinic and food packages. All relevant social support costs from the PIH NCD budgets were totalled for the year.

\section{Labour}

We identified all paid staff supporting the NCD programme, including cashiers, an archivist, plumbers, data managers, drivers, laboratory technicians, electricians, physicians, pharmacist, nurses and cleaning staff. The annual salary for each position was assessed and then multiplied by the percentage of time dedicated to the NCD clinic. The cost of the visiting consultants, the cardiologist and endocrinologist, including allowances for transportation and accommodation was determined and included in the total labour cost. Although volunteer labour is occasionally provided by visiting doctors, volunteer labour was not included in this analysis. It is important to note that the nurses spent around $50 \%$ of their time on training, mentoring and supervising staff at lower-level facilities, and not on direct patient care. Since only $50 \%$ of their time is spent providing clinical care at the district-level NCD clinic, only $50 \%$ of their total salary is included in the labour cost.

\section{Disease-specific cost per patient}

The number of patients per disease type, including DM, HTN, HF and CRD, and number of visits in the fiscal year were determined. Severity for each disease type was determined based on first clinic visit in the study period. The total cost of laboratory and medications per disease type was determined as detailed above, and then divided by the total number of patients in each disease category to determine a per-patient cost for each of the four disease categories. Cost of consumables specific to a particular disease type, such as consultant fees for DM and HF, and disease-specific consumables (eg, peak flow meters) was totalled and divided by the number in that disease category. Otherwise, all shared consumables were divided by total number of patients with NCD. All other costs, including the annualised facilities and maintenance cost, labour cost and social support cost, were divided by the number of total patients with NCD. Only $50 \%$ of the cost of the nurses' total labour was attributed to disease-specific costs per patient. All components were summed to determine the annual cost per patient per disease type.

\section{Patient and public involvement}

Patients were not involved in this study.

\section{RESULTS}

We determined that the start-up cost of the NCD clinic to support initial implementation was US\$47 976 (US\$0.16 per capita). Costs included construction of the clinic space, baseline training, and purchase of clinic

\begin{tabular}{lc|}
\hline Table 1 Non-communicable disease clinic start-up costs \\
\hline Cost component & Total cost (US\$) \\
\hline Construction of NCD clinic & 12633 \\
Baseline NCD training & 10824 \\
Training cost per nurse & 5412 \\
Transportation & 500 \\
Accommodation & 1071 \\
Food & 3000 \\
Training materials & 330 \\
Trainer fees & 466 \\
Communication fees & 45 \\
Clinic equipment and supplies & 24519 \\
Furniture & 1495 \\
BP cuff, patient scale, peak flow & 476 \\
meter, glucometer & \\
Ultrasound equipment & 19500 \\
INR machine† & 490 \\
HbA1c POC machine $\neq$ & 275 \\
Computers/printer & 1471 \\
Charts/office supplies & 812 \\
Butaro NCD start-up cost & 47976 \\
\hline
\end{tabular}

${ }^{*}$ Cardiac ultrasound purchased was SonoSite MicroMaxx (SonoSite, Bothell, Washington, USA) portable ultrasound machine (US\$15 500) with 5-1 MHz and 8-4 MHz probes for adult and paediatric studies (US\$3000). Price of 6000 denotes price of hand-held Lumify Ultrasound system (Phillips, Cambridge, Massachusetts, USA).

†INR machine used Is Coagucheck Pro II (Roche Diagnostics, Indianapolis, Indiana, USA).

$\ddagger$ Point-of-care HbA1c machine is SD A1c Care (SD BIOSENSOR, Gyeonggi-do, Republic of Korea).

$\mathrm{BP}$, blood pressure; HbA1c, haemoglobin A1c; INR, international normalised ratio; NCD, non-communicable disease; POC, point of care.

equipment and supplies. Details regarding initial start-up cost are shown in table 1 .

The annual operating cost of the NCD clinic was determined to be US\$68 975 (US\$0.23 per capita). Operating costs are detailed in table 2 . Between July 2013 and June 2014, 632 patients with NCD were seen at the Butaro NCD clinic; 91 were newly enrolled. The cohort was majority female $(66.7 \%)$. The mean age was 51 years, with $8.5 \%$ paediatric (age $<18$ years). Among adults, the average body mass index was $22.8 \mathrm{~kg} / \mathrm{m}^{2}$.

Labour and medications were the most significant cost drivers for the programme. Labour was the largest cost driver, comprising $54 \%$ of the total cost, followed by medications at $17 \%$, and facilities and maintenance cost at $12 \%$. Laboratory testing, training and miscellaneous consumables combined costs accounted for $10 \%$ of the total cost. Laboratory costs were $6 \%$ of the total costs, with a total cost of US $\$ 4500$. Unit cost of medication and laboratory tests are summarised in online supplemental 
Table 2 Operating costs for the non-communicable disease clinic across all categories for fiscal year 2013-2014

\begin{tabular}{|c|c|c|c|}
\hline Cost category & Cost (US\$) & \% Effort & $\begin{array}{l}\text { Proportion } \\
\text { of total cost } \\
(\%)\end{array}$ \\
\hline Labour & 36980.08 & & 54 \\
\hline Staff & 31923.70 & & \\
\hline Archivist & 148.05 & 5 & \\
\hline Cashier & 236.89 & 8 & \\
\hline Billing officer & 148.05 & 5 & \\
\hline Data officer & 3626.10 & 1 & \\
\hline Electrician & 65.80 & 2 & \\
\hline $\begin{array}{l}\text { Laboratory } \\
\text { technician }\end{array}$ & 461.54 & 20 & \\
\hline Pharmacist & 1395.85 & 20 & \\
\hline Physician & 4193.62 & 30 & \\
\hline Nurse (AO level) & 10419.56 & 50 & \\
\hline Nurse (A1 level) & 6935.13 & 50 & \\
\hline Plumber & 52.37 & 2 & \\
\hline Social worker & 1085.68 & 30 & \\
\hline Stock manager & 360.10 & 5 & \\
\hline $\begin{array}{l}\text { Cleaning } \\
\text { cooperative }\end{array}$ & 2794.96 & 4 & \\
\hline $\begin{array}{l}\text { Supervising } \\
\text { consultants }\end{array}$ & 5056.38 & 5 & \\
\hline Medications & 11420.17 & & 17 \\
\hline $\begin{array}{l}\text { Facility and } \\
\text { maintenance }\end{array}$ & 8528.36 & & 12 \\
\hline Social services† & 5786.35 & & 8 \\
\hline Transportation & 2077.15 & & \\
\hline Food packages & 3709.20 & & \\
\hline Laboratory testing & 4496.53 & & 6 \\
\hline $\begin{array}{l}\text { Miscellaneous } \\
\text { consumables }\end{array}$ & 1315.88 & & 2 \\
\hline $\begin{array}{l}\text { NCD refresher training } \\
\text { (two nurses) }\end{array}$ & 447.73 & & 1 \\
\hline $\begin{array}{l}\text { Total annual operating } \\
\text { costs }\end{array}$ & 68975.10 & & 100 \\
\hline
\end{tabular}

A0-level nurses have received 3 years of post-secondary education; A1-level nurses have received secondary-school vocational training in nursing.

*Facility and maintenance cost includes sewage, electricity, plumbing, equipment maintenance and repair, security, landscaping, cleaning, office supplies, communications fees, taxes and bank fees.

†During the study period, $27.2 \%$ of patients received social services (16.1\% transportation support, $11.1 \%$ food packages). NCD, non-communicable disease.

table 1 . The proportions of cost by category are displayed in figure 1.

In terms of per-patient costing, DM had the highest annual cost per patient at US\$151, which was largely driven by its medication cost, which was US $\$ 58$ per patient per year (table 3 ). Nearly half of patients with diabetes

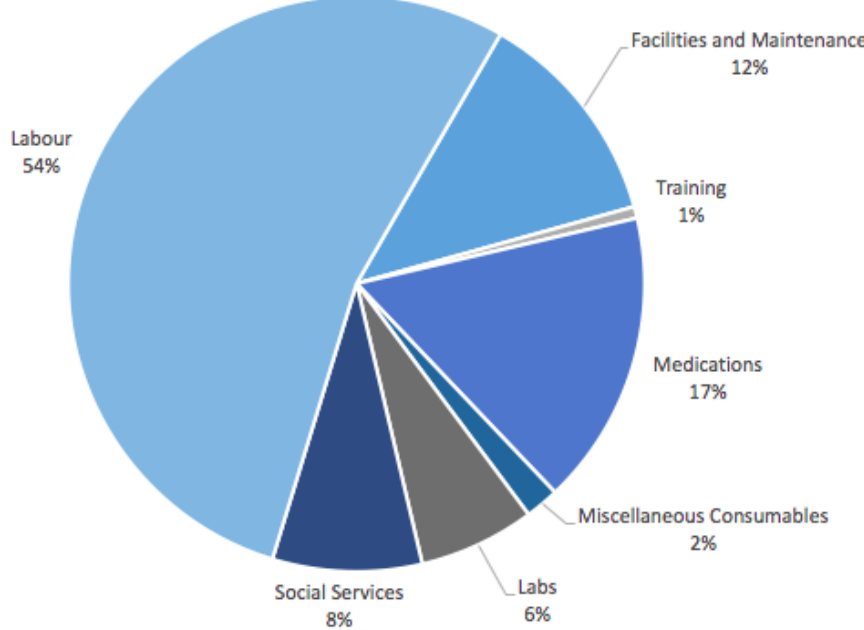

Figure 1 Total annual programme operating costs for the non-communicable disease clinic by category.

were on insulin therapy. HF had the second highest cost per patient at US $\$ 104$, which was driven by medication cost (US\$18 per patient per year), and, similar to DM, increased laboratory testing and higher operating cost due to consultant fees. Annual disease-specific cost per patient as well as components of the cost are detailed in table 3 .

\section{DISCUSSION}

This study is the first to evaluate the start-up and annual operating financial costs for a 'PEN-Plus' clinic at a rural public sector district hospital in Rwanda. Using a microcosting methodology, this study provides needed information representative of real-world integrated care for severe NCDs in a resource-restricted setting. The start-up costs of this advanced clinic, including training, equipment and supplies, could be estimated to be as low as US\$24 000 if there were already available space, furniture, general ultrasound and laboratory devices for chemistries, including HbAlc testing. Start-up costs could be as high as an estimated US\$60 000 if none of these elements were available initially and purchase of a point-of-care electrolyte machine for laboratory evaluation was needed.

Quality services for severe chronic NCDs such as type 1 diabetes and advanced rheumatic heart disease are largely restricted to major referral centres in sub-Saharan Africa. ${ }^{20}$ Over the past decade, through a strategy we have described as 'PEN-Plus', the RMOH, with support from IMB/PIH, has worked to decentralise chronic care for these conditions to rural district-hospital outpatient clinics in an integrated fashion. ${ }^{11}{ }^{22}$ In an attempt to increase access and reduce costs, this service delivery model relied on specially trained nurses working in the public system to deliver care normally provided only by specialised physicians at urban centres. Quality was reinforced through supportive supervision by local generalist physicians and visiting cardiologists and 
endocrinologists. We previously have demonstrated the feasibility and validity of nurse-performed diagnosis and management of such complex conditions as type $1 \mathrm{DM}$ and HF. ${ }^{11-1323}$ These results now support the affordability of this approach and will be useful considerations in the advocacy for implementation of such models in similar settings.

It is important to note that training start-up costs in this clinic were relatively low per nurse (US\$5412) because of the availability of a previously established training facility for didactics and precepted clinical experiences at another site in the country. The start-up costs for training the very first cohort of nurses in the country and establishing a training facility were higher as they required more time of specialists such as cardiologists and endocrinologists who had skills in echocardiography, HF and insulin management. These costs are not described here.

The annual operating costs of the clinic to manage 632 patients and provide training, mentorship and supervision to health centres were found to be US $\$ 69000$ per year, including full-time staff, supervising physicians, social assistance, facilities and maintenance, medications and laboratory testing, and continuous professional education. The largest component of these costs were fixed costs in labour (54\%) and facilities and maintenance $(12 \%)$. Nurses and generalist physician salaries comprised almost $70 \%$ of the labour costs. Therefore, per-patient costs in the 'PEN-Plus' clinics were likely to be significantly lower than the costs of providing the same services through more highly paid specialist physicians at tertiary referral centres assuming productivity was similar. ${ }^{24}$ Per-patient costs could be further reduced if patient volumes increased.

This study is limited by the perspective of the analysis; it was performed from the perspective of the health system, not the patient. The study does not reflect, for example, indirect medical costs such as transportation for those who did not receive social services, or non-medical costs such as lost wages to attend the clinic. We calculated costs in 2014 exchange-rate US dollars and did not adjust for purchasing power parity. Labour and other non-tradable costs may be different in other countries. Additionally, this study looked only at outpatient costs, but did not capture the cost of hospitalisations. Salaries of volunteer practitioners that aided in training and start-up are not quantified. Turnover in nurses will require higher annual costs for repeat baseline training. Based on global burden of disease estimates of the prevalence of moderate to severe $\mathrm{HF}$, our service coverage is estimated at $63 \%-90 \%$ in our catchment area. ${ }^{25}$ It may be possible to increase patient volume with active case finding in the community, which could change the per-capita cost. This study focused on a single centre in Rwanda.

\section{CONCLUSION}

The results from this study provide important evidence for public sector planners in low-income countries as

Table 3 Annual cost per patient by disease subcategory $(n=632)$

\begin{tabular}{|c|c|c|c|c|c|c|c|c|}
\hline Disease subgroup & $\begin{array}{l}\text { Number } \\
\text { of } \\
\text { patients }\end{array}$ & $\begin{array}{l}\text { Mean } \\
\text { number of } \\
\text { visits* }^{*}\end{array}$ & $\begin{array}{l}\text { NCD } \\
\text { medication } \\
\text { cost (US\$) }\end{array}$ & $\begin{array}{l}\text { Disease- } \\
\text { specific } \\
\text { consumables } \\
\text { (US\$) }\end{array}$ & $\begin{array}{l}\text { Shared } \\
\text { consumables } \\
\text { (US\$) }\end{array}$ & $\begin{array}{l}\text { Laboratories } \\
\text { (US\$) }\end{array}$ & $\begin{array}{l}\text { Operating } \\
\text { cost } \\
\text { (US\$)† }\end{array}$ & $\begin{array}{l}\text { Total per- } \\
\text { patient } \\
\text { cost (US\$) }\end{array}$ \\
\hline On Insulin & 44 & & & & & & & \\
\hline Congestive heart failure & 204 & 5.3 & 18.09 & 0.09 & 2.03 & 8.45 & 75.80 & 104.47 \\
\hline NYHA I-II & 65 & & & & & & & \\
\hline NYHA III-IV & 68 & & & & & & & \\
\hline $\begin{array}{l}\text { Chronic respiratory } \\
\text { disease }\end{array}$ & 114 & 3 & 8.51 & 0.09 & 2.03 & 0 & 58.66 & 69.30 \\
\hline None/unknown & 72 & & & & & & & \\
\hline Hypertension & 223 & 2.7 & 6.80 & 0 & 2.03 & 5.95 & 58.66 & 73.44 \\
\hline None/unknown & 76 & & & & & & & \\
\hline Stage I-II & 134 & & & & & & & \\
\hline Stage III-IV & 13 & & & & & & & \\
\hline Total & 632 & & & & & & & \\
\hline
\end{tabular}

*Per fiscal year of 2014

†Operating cost excluding medication cost, consumables and laboratories. Consultant cost only applied to patients with congestive heart failure and type 2 diabetes mellitus.

NCD, non-communicable disease; NYHA, New York Heart Association. 
they expand services on the path to Universal Health Coverage. An initial target to achieve high levels of service availability for severe chronic NCDs at first-level hospitals has several advantages. First, this 'PEN-Plus' strategy addresses equity concerns by targeting severe conditions and increasing access to the rural poor through decentralisation of quality care previously available only at urban referral centres. Second, the budget impact of this strategy is relatively low both in terms of start-up and operational costs. Third, this strategy provides a foundation of leadership and expertise necessary to further decentralise and integrate care for more common and less severe NCDs such as uncomplicated HTN, asthma and non-insulin-dependent DM to primary health centres through the WHO PEN approach.

\section{Author affiliations}

'Department of Medicine, Division of Global Health Equity, Brigham and Women's Hospital, Boston, Massachusetts, USA

${ }^{2}$ Inshuti Mu Buzima, Partners In Health - Rwanda, Rwinkwavu, Rwanda

${ }^{3}$ Organizational Transformational Initiatives, Greenville, South Carolina, USA

${ }^{4}$ Partners In Health, Boston, Massachusetts, USA

${ }^{5}$ Department of Medicine, Section of Cardiology, Boston University, Boston, Massachusetts, USA

${ }^{6}$ Department of Global Health and Social Medicine, Program in Global NCDs and

Social Change, Harvard Medical School, Boston, Massachusetts, USA

${ }^{7}$ Department of Internal Medicine, Endocrinology Unit, School of Medicine and

Pharmacy, College of Medicine and Health Sciences, University of Rwanda, Kigali, Rwanda

${ }^{8}$ Department of Pediatrics, Pediatric Cardiology Unit, School of Medicine and

Pharmacy, College of Medicine and Health Sciences, University of Rwanda, Kigali, Rwanda

${ }^{9}$ Department of Paediatrics, King Faisal Hospital, Kigali, Rwanda

${ }^{10}$ Ministry of Health, Kigali, Rwanda

Contributors Conception and design: LAE, GB, GK, PHP, CCN, ER, JM, TM, LN, CB. Data collection: LAE, CR, LN, FM, GN, CG, EM, JCM, JPM, HH, TA, GN, SD. Analysis and data interpretation: LAE, GK, GB, PHP, TA, GN, CCN, LN, CM. The first draft of the manuscript was written by LAE with subsequent revisions by LAE and GB. All authors contributed to the revision of and approved the final version of the submitted manuscript.

Funding The authors have not declared a specific grant for this research from any funding agency in the public, commercial or not-for-profit sectors.

Competing interests None declared.

Patient consent for publication Not required

Ethics approval Ethical approval was obtained by the Rwanda National Ethics Committee and Institutional Review Board of Brigham and Women's Hospital.

Provenance and peer review Not commissioned; externally peer reviewed.

Data availability statement Data are available on reasonable request.

Open access This is an open access article distributed in accordance with the Creative Commons Attribution Non Commercial (CC BY-NC 4.0) license, which permits others to distribute, remix, adapt, build upon this work non-commercially, and license their derivative works on different terms, provided the original work is properly cited, appropriate credit is given, any changes made indicated, and the use is non-commercial. See: http://creativecommons.org/licenses/by-nc/4.0/.

\section{REFERENCES}

1. Ottersen T, Norheim OF, World Health Organization Consultative Group on Equity and Universal Health Coverage. Making fair choices on the path to universal health coverage. Bull World Health Organ 2014;92.
2. Tracking universal health coverage. First global monitoring report. Geneva World Health Organization; 2015.

3. Bukhman G, Mocumbi AO, Horton R. Reframing NCDS and injuries for the poorest billion: a Lancet Commission. Lancet 2015;386:1221-2.

4. Stenberg K, Hanssen O, Edejer TT-T, et al. Financing transformative health systems towards achievement of the health sustainable development goals: a model for projected resource needs in 67 lowincome and middle-income countries. Lancet 2017.

5. Bertram MY, Sweeny K, Lauer JA, et al. Investing in noncommunicable diseases: an estimation of the return on investment for prevention and treatment services. Lancet 2018;391:2071-8.

6. World Health Organization. Scaling up action against noncommunicable diseases: how much will it cost? Geneva: World Health Organization, 2011. Available: http://www.who.int/iris/handle/ 10665/44706

7. Murray CJL, Lauer JA, Hutubessy RCW, et al. Effectiveness and costs of interventions to lower systolic blood pressure and cholesterol: a global and regional analysis on reduction of cardiovascular-disease risk. Lancet 2003;361:717-25.

8. Soliman EZ, Mendis S, Dissanayake WP, et al. A polypill for primary prevention of cardiovascular disease: a feasibility study of the World Health Organization. Trials 2011;12.

9. WHO. Package of essential noncommunicable (PEN) disease interventions for primary health care in low-resource settings. Geneva World Health Organization; 2010

10. Implementation tools. Package of essential noncommunicable (PEN) disease interventions for primary health care in low-resource settings. Geneva World Health Organization; 2013: pp. 1-210.

11. Bukhman G, Kidder A, eds. The Partners In Health Guide to Chronic Care Integration for Endemic Non-Communicable DiseasesRwanda Edition. Boston, MA: Partners in Health, 2011.

12. Kwan GF, Bukhman AK, Miller AC, et al. A simplified echocardiographic strategy for heart failure diagnosis and management within an integrated noncommunicable disease clinic at district hospital level for sub-Saharan Africa. JACC Heart Fail 2013;1:230-6.

13. Eberly LA, Rusingiza E, Park PH, et al. Nurse-driven echocardiography and management of heart failure at district hospitals in rural Rwanda. Circ Cardiovasc Qual Outcomes 2018;11:1-5.

14. Rusingiza EK, El-Khatib Z, Hedt-Gauthier B, et al. Outcomes for patients with rheumatic heart disease after cardiac surgery followed at rural district hospitals in Rwanda. Heart 2018;104:1707-13.

15. Habineza H, Mutumbira C, Hedt-Gauthier BL, et al. Treating persistent asthma in rural Rwanda: characteristics, management and 24-month outcomes. Int J Tuberc Lung Dis 2017;21:1176-82.

16. Tapela Net al. Diabetes in rural Rwanda: high retention and positive outcomes after 24 months of follow-up in the setting of chronic care integration. Int J Diabetes Clin Res 2016;3:1-6.

17. National Institute of Statistics of Rwanda (NISR). Ministry of Finance and Economic Planning (MINECOFIN). Rwanda Rwanda Fourth Population and Housing Census; 2012.

18. Ndayisaba A, Harerimana E, Borg R, et al. A clinical mentorship and quality improvement program to support health center nurses manage type 2 diabetes in rural Rwanda. J Diabetes Res 2017;2017:1-10.

19. Gupta N, Bukhman G. Leveraging the lessons learned from HIV/ AIDS for coordinated chronic care delivery in resource-poor settings. Healthcare 2015;3:215-20.

20. Carlson S, Duber HC, Achan J, et al. Capacity for diagnosis and treatment of heart failure in sub-Saharan Africa. Heart 2017;103:1874-9.

21. Bukhman G, Bavuma C, Gishoma C, et al. Endemic diabetes in the world's poorest people. Lancet Diabetes Endocrinol 2015;3:402-3.

22. Harvard Medical School and Partners in Health co-host session with World Health Organization on addressing gaps for severe NCDs such as Type 1 Diabetes through "PEN-Plus" strategies at WHO AFRO in Dakar, Senegal [Internet]. Dakar, Senegal NCD Synergies; 2018. http://ncdsynergies.org/harvard-medical-school-afro-session/

23. Eberly LA, Rusingiza E, Park PH, et al. 10-Year heart failure outcomes from nurse-driven clinics in rural sub-Saharan Africa. $J$ Am Coll Cardiol 2019;73:977-80.

24. Feachem RG, Kjellstrom T, Murray CJL, et al. The health of adults in the developing world. New York: Oxford University Pres, 1992.

25. IHME (Institute for Health Metrics and Evaluation). Global burden of disease 2016 data visualizations, 2017. Available: http://viz.healthme tricsandevaluation.org/gbd-compare/ [Accessed 12 Mar 2019]. 